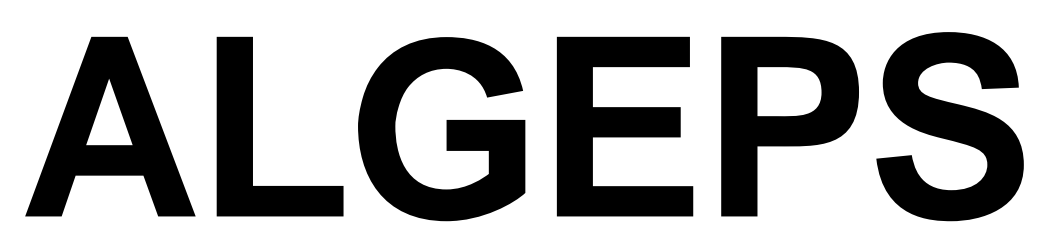

REVISTA DE GEOLOGIA, SĖRIE B no 595 - Juliol del 2012

RECORRIDO DESDE ANDORRA A VALDEARIÑO, ARIÑO Y ALBALATE DEL ARZOBISPO, A TRAVÉS DEL PATRIMONIO GEOLÓGICO Y MINERO DE LAS COMARCA DE ANDORRA SIERRA DE ARCOS, TERMINANDO EN LA COMARCA DEL BAJO MARTÍN

Josep M. Mata-Perelló

Aquest recorregut va ésser experimentat amb docents el dia 1 DE SETEMBRE DEL 2010 


\section{RECORRIDO DESDE ANDORRA A VALDEARIÑO, ARIÑO Y ALBALATE DEL ARZOBISPO, A TRAVÉS DEL PATRIMONIO GEOLÓGICO Y MINERO DE LAS COMARCA DE ANDORRA - SIERRA DE ARCOS, TERMINANDO EN LA COMARCA DEL BAJO MARTÍN}

Por Josep M. Mata-Perelló

\section{ADVERTENCIAS PREVIAS}

Como en otros recorridos de RECONOCIMIENTO GEOLÓGICO (o de RECONOCIMIENTO GEOLÓGICO Y MINERO), el recorrido se compondrá de diversas PARADAS. En este caso serán ocho.

Por otra parte, habrá que tener en cuenta, en todo momento, especialmente antes de empezar los recorridos de los diferentes tramos, el estado de los caminos y carreteras, por donde transitará el recorrido. Al respecto, cabe decir que prácticamente todos estos tramos se halla en buenas condiciones.

Finalmente, como ya hacemos en otros recorridos similares, queremos decir que hace falta tener un cuidado muy especial en el respeto a la naturaleza, a lo largo de todo el recorrido del itinerario, y también fuera de él.

\section{BREVE INTRODUCCIÓN GEOLÓGICA}

El recorrido de este itinerario, se desarrollará por una de las tres unidades geológicas que constituyen el suelo y el subsuelo de Aragón. Concretamente por el Sistema Ibérico o Cordillera Ibérica, aunque terminará en el contacto entre y la Depresión Geológica del Ebro.

Así, a lo largo de todo de todo el recorrido del itinerario, se irán encontrando afloramientos de los materiales mesozoicos, fundamentalmente del Cretácico. Y más concretamente del Albiense, en la mayoría de las ocasiones. Al final, en contacto con estos se encontraran afloramientos de los materiales cenozoicos, del tránsito del Oligoceno al Mioceno, pero fuera ya de la comarca de Andorra - Sierra de ArcosAsimismo, a menudo, encontraremos afloramientos de los materiales detríticos cuaternarios, por encima de los anteriores

\section{BREVE INTRODUCCIÓN GEOGRÁFICA}


El recorrido del presente itinerario se efectuará casi exclusivamente por una comarca aragonesa, la de la Andorra - Sierra de Arcos. Así, se iniciará en la propia capital comarcal, en la población de Andorra, para dirigirse luego hacía el Este, por el Valdeariño, llegando luego a Ariño. El último tramo, muy breve, se realizará por la comarca del Bajo Martín.

En este recorrido, se circulará por los términos municipales de: Andorra, Alloza, Ariño y Albalate del Arzobispo. Los tres primeros de la comarca de Andorra - Sierra de Arcos y el último de la del Bajo Martín.

Esta comarca, gravita en torno a dos ríos de la misma cuenca: el Martín y el Guadalope. El primero recoge las aguas de los sectores meridionales, centrales y orientales; mientras que el segundo recoge las aguas de los sectores más septentrionales de la comarca.

\section{OBJETIVOS GENERALES DE ESTE ITINERARIO}

En este itinerario, los objetivos generales que se han de conseguir, se pueden concretar en los siguientes aspectos:

1.- Estudio y reconocimiento de los materiales mesozoicos (en buena parte del Cretácico y en menor del Triásico y Jurásico, según los lugares) situados en el Sistema Ibérico, que iremos encontrando a lo largo del recorrido del itinerario, entre las inmediaciones de Andorra y Albalate del Arzobispo.

2.- Estudio y reconocimiento de los materiales cenozoicos (del Oligoceno) situados en la Depresión Geológica del Ebro, que veremos en la parte final del recorrido, en las inmediaciones de Albalate del Arzobispo.

3.- Estudio y observación del Sistema Ibérico y de sus relaciones con la Depresión Geológica del Ebro.

4.- Visión de algunas de las antiguas explotaciones encontradas a lo largo del recorrido del itinerario. En concreto de:

4A) de diversas explotaciones de lignito, situadas en los municipios de Andorra, Alloza y Ariño, entre los afloramientos mesozoicos.

4B) de diversas explotaciones de gravas cuaternarias, situadas en el valle del río Martín, en las inmediaciones de Ariño.

5.- Observación del impacto producido por las actividades mineras. I de las restauraciones realizadas para paliar este impacto.

6.- Observación de la surgencia de aguas termales en los Baños, dentro del municipio de Ariño.

7.- Visión de los diferentes lugares directamente relacionados con el Patrimonio Geológico y Minero que iremos encontrando a lo largo del recorrido del presente itinerario. Dentro del primero cabe mencionar el relacionado con la surgencia de aguas 
termales y con el estrecho del río Martín. Dentro del segundo, cabe mencionar el Museo Minero de Andorra y las interesantes Restauraciones Mineras de Corta Barrabasa.

\section{ANTECEDENTES BIBLIOGRÁFICOS}

En relación con este itinerario, no conocemos ningún antecedente, relativo a otro itinerario que discurra por este lugar. En este sentido, este itinerario ya constituye un antecedente, si no estamos equivocados. Todo ello salvo tres trabajos nuestros: MATAPERELLÓ (2002, 2003 y 2009). Asimismo, existen otros antecedentes parciales nuestros en: MATA-PERELLÓ (1996 y 1997).

Por otra parte, tenemos otros antecedentes nuestros, en relación a las mineralizaciones presentes en esta zona. Se trata de MATA-PERELLÓ (1991a, 1991b y 1991c), dedicados a los inventarios mineralógicos de estas comarcas.

En relación con las características geológicas citaremos el trabajo de PEÑA et altri (1984). Asimismo, en relación al patrimonio geológico citaremos el trabajo de BURILLO (1996), así como el publicado por la GADMA (2001).

Todos estos trabajos se hallaran debidamente relacionados en el apartado de REFERENCIAS BIBLIOGRÁFICAS, que figura al final del presente trabajo

\section{RECORRIDO DEL ITINERARIO}

Indicaremos, a continuación un itinerario orientativo, el cual discurriría por diferentes lugares de las comarcas anteriormente citadas. Así, el recorrido se iniciará en Andorra (en la comarca de la Sierra de Arcos - Andorra), discurriendo hacía Ariño (en la mima comarca). En este recorrido, por la denominada Valdeariño se realizaran diversas paradas.

Luego, el recorrido efectuará una hijuela hacía la Sima de San Pedro (de Oliete), entrando brevemente en la comarca de las Cuencas Mineras. Tras realizar la parada se retornará a Ariño. Desde ahí, el recorrido continuará junto al río Martín hasta el pueblo de Albalate del Arzobispo. En este recorrido se efectuaran diversas paradas, pasando el itinerario de la comarca de la Sierra de Arcos - Andorra a la comarca del Bajo Martín. En esta última finalizará, tras realizarse diversas paradas.

\section{DESCRIPCIÓN DEL ITINERARIO}

Como de costumbre, estructuraremos el recorrido del itinerario en una serie de PARADAS, que a continuación iremos viendo. En cada una de estas paradas haremos un breve comentario (geológico o mineralógico, según acontezca).

Por otra parte, en cada caso indicaremos (entre paréntesis) la hoja topográfica en donde se halla la parada. Para ello, utilizaremos las hojas del Instituto Geográfico y 
Catastral de España, publicadas a la escala de 1:50.000. En este caso, las dos hojas que utilizaremos serán las siguientes: 467 (o de Albalate del Arzobispo) 493 (o de Oliete), 494 (o de Calanda).

Así pues, la relación de las paradas que componen el recorrido de este itinerario, son las siguientes:

PARADA 1. POZO DE SAN JUAN, (término municipal de Andorra, comarca de la Sierra de Arcos - Andorra). (Hoja 494).

El recorrido del presente itinerario geológico lo realizaremos en la población de Andorra, la capital de la comarca de la Serra de Arcos - Andorra. Desde la misma población, nos convendrá ir hasta el lugar en donde se halla el antiguo Pozo de San Juan. Para efectuar ahí la primera parada del recorrido, apenas a 1’5 Km de la población.

Andorra se encuentra sobre afloramiento de los materiales cenozoicos de la Depresión Geológica del Ebro, los cuales recubren a los mesozoicos (fundamentalmente cretácicos) de la Rama Aragonesa del Sistema Ibérico. Estos últimos afloran en las cercanías de Andorra.

En este lugar se hallaba un antiguo pozo minero, el denominado Pozo de San Juan, por el que se llegaba a los niveles mesozoicos situados bajo los cenozoicos. En concreto, se llegaba a los materiales cretácicos del Albiense, a los de la Formación Escucha, en donde se hallan los niveles lignitíferos explotados en diferentes lugares de la cuenca. Recientemente, los alrededores del pozo minero han sido muy bien habilitados como Museo de la Minería del Pozo de San Juan. 


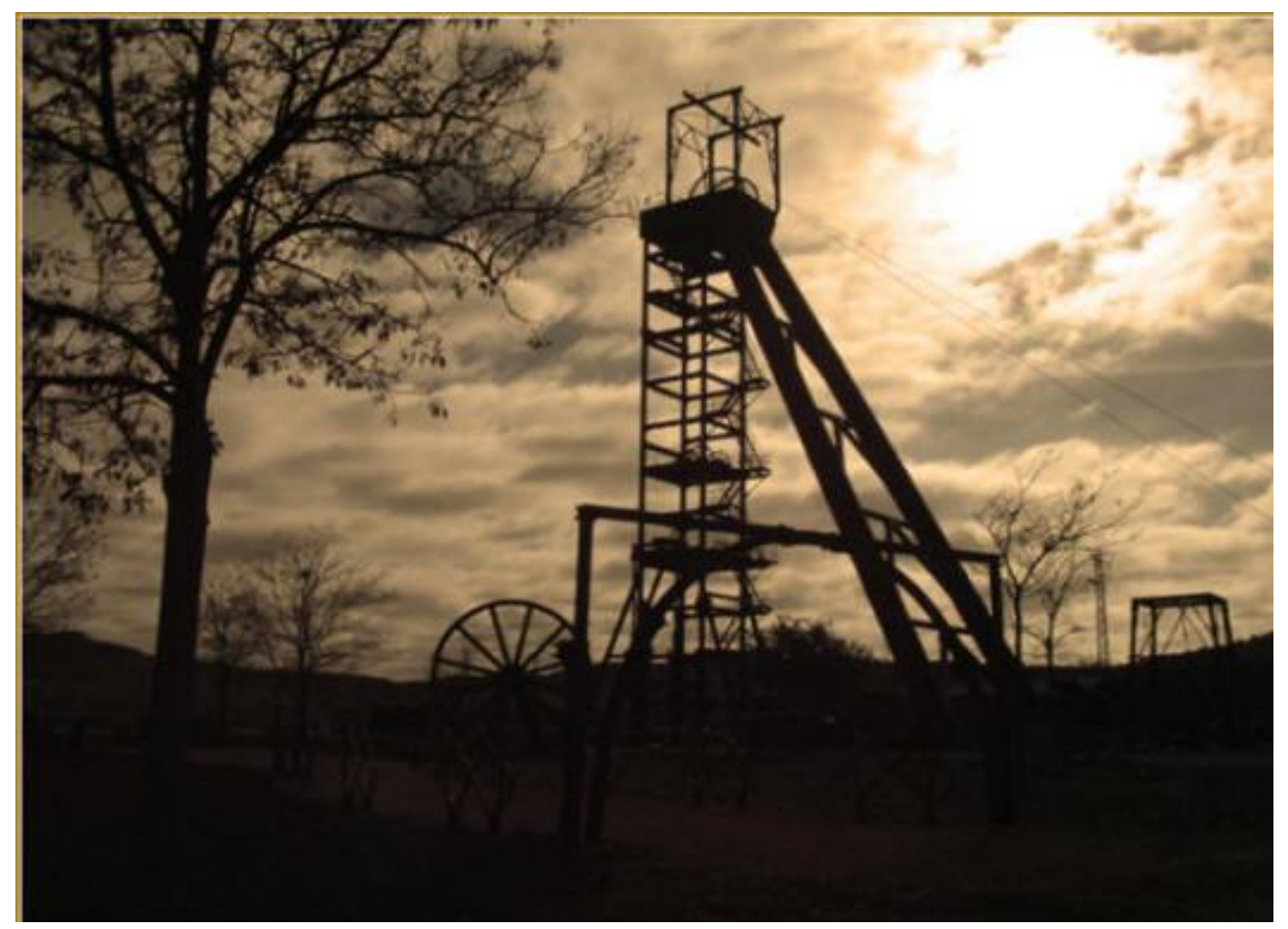

Fotografía del Pozo de San Juan utilizada para el tríptico del Congreso de la SEDPGYM (Andorra, 25 - 28 de Septiembre del 2008)

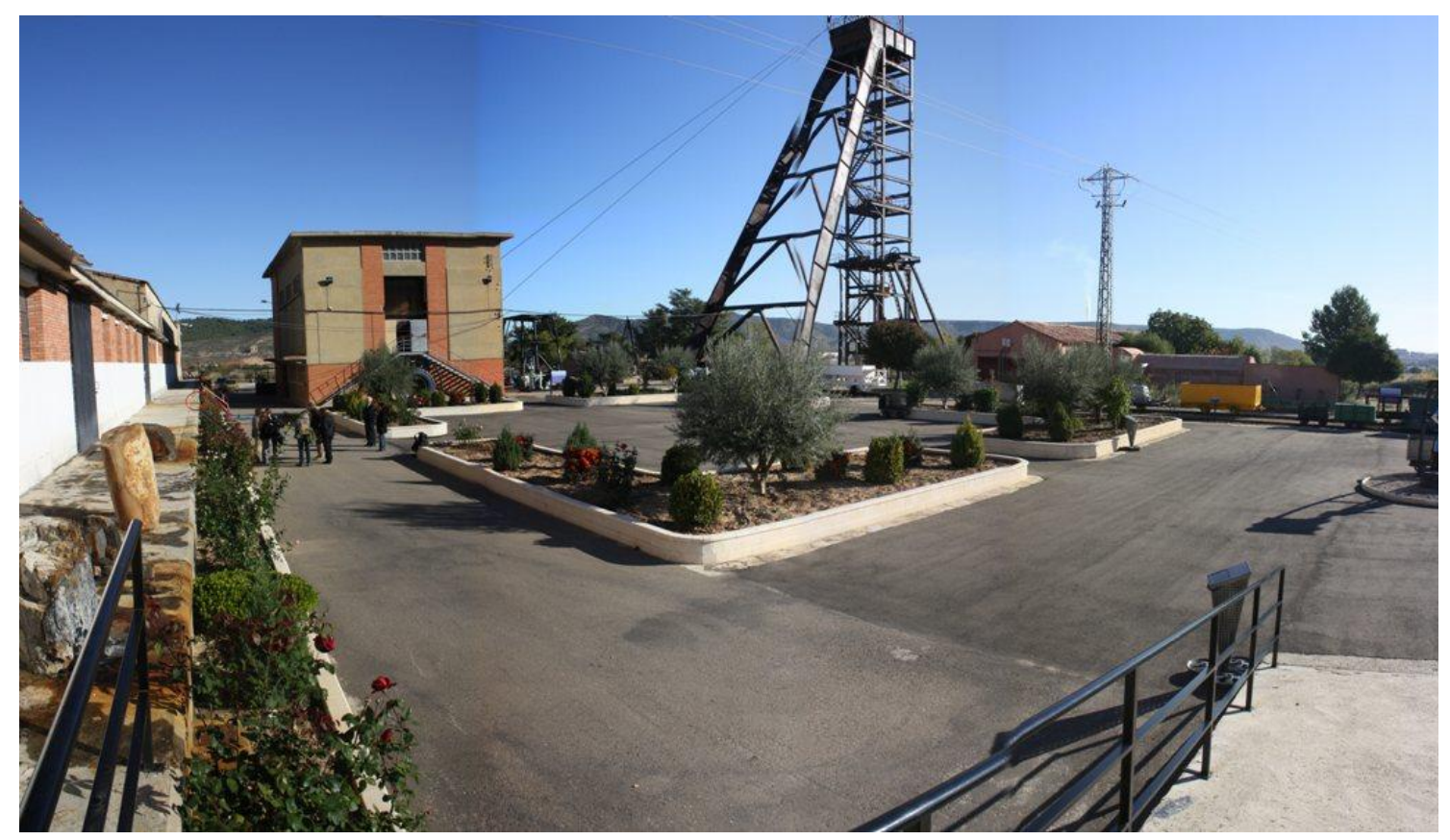

Otro aspecto del Museo Minero

(Fotografía de Kamal Tarquisti, Congreso de Ariño, 2010) 
PARADA 2. RESTAURACIONES DE LA CORTA BARRABASA, (término municipal de Andorra, comarca de la Sierra de Arcos - Andora). (Hoja 494).

Después de realizar la parada anterior, cabe regresar a Andorra. Desde ahí nos convendrá salir por la carretera de Albalate del Arzobispo (1 Km, apenas), hasta encontrar la carretera de las minas. Ésta va a Valdeariño y al pueblo de Ariño. Al poco de tomarla, llegaremos a la zona es donde quedan los restos de la antigua explotación de la Corta Barrabasa, en buena parte ya restaurada. En esta zona efectuaremos una nueva parada, a unos $3-4 \mathrm{Km}$ de la anterior. Ahí podremos ver las restauraciones realizadas en las escombreras de las minas, convirtiéndolas en tierras de labor.

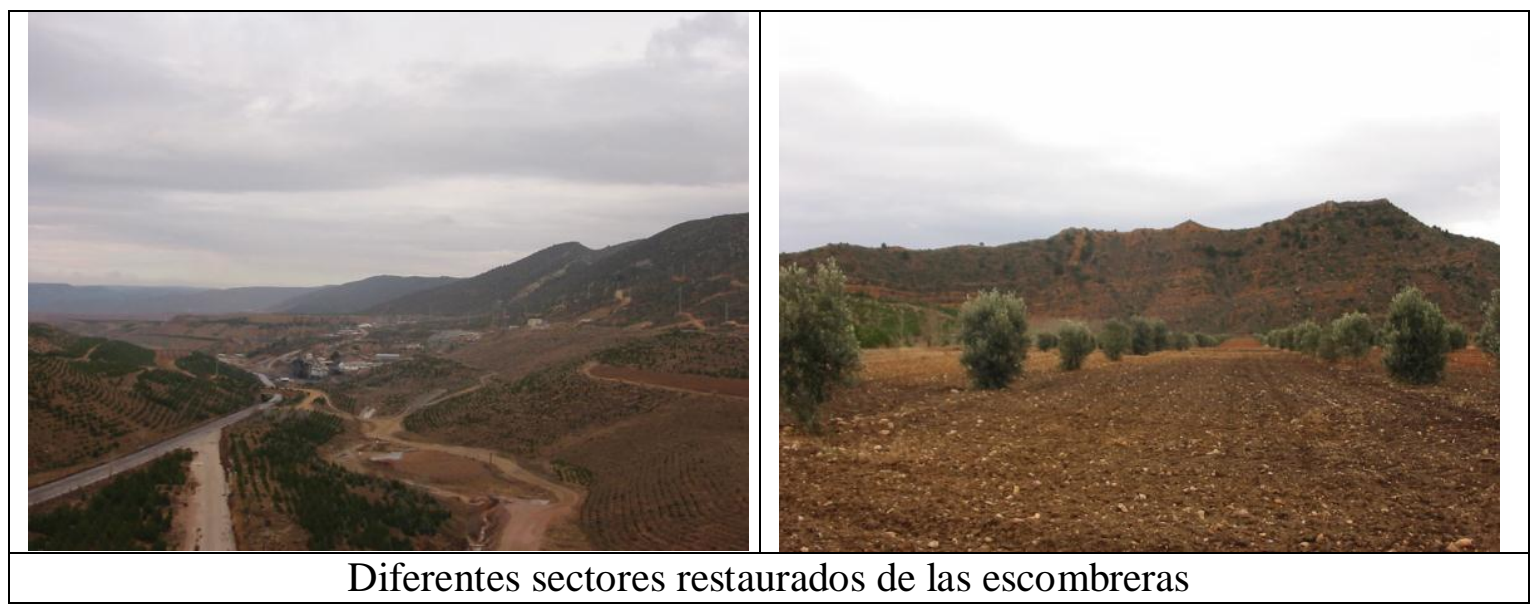

Por otra parte, en este recorrido iremos encontrando, en un principio afloramientos de los materiales cenozoicos cubriendo a los mesozoicos. Al tomar la carretera que conduce a las minas, empezaremos a encontrar afloramientos de los niveles versicolores de los caolines y arenas de la Formación Utrillas, del Albiense; es decir del Cretácico. Luego, al llegar a la corta, por debajo de estos materiales aparecen los niveles lignitíferos de la Formación Escucha.

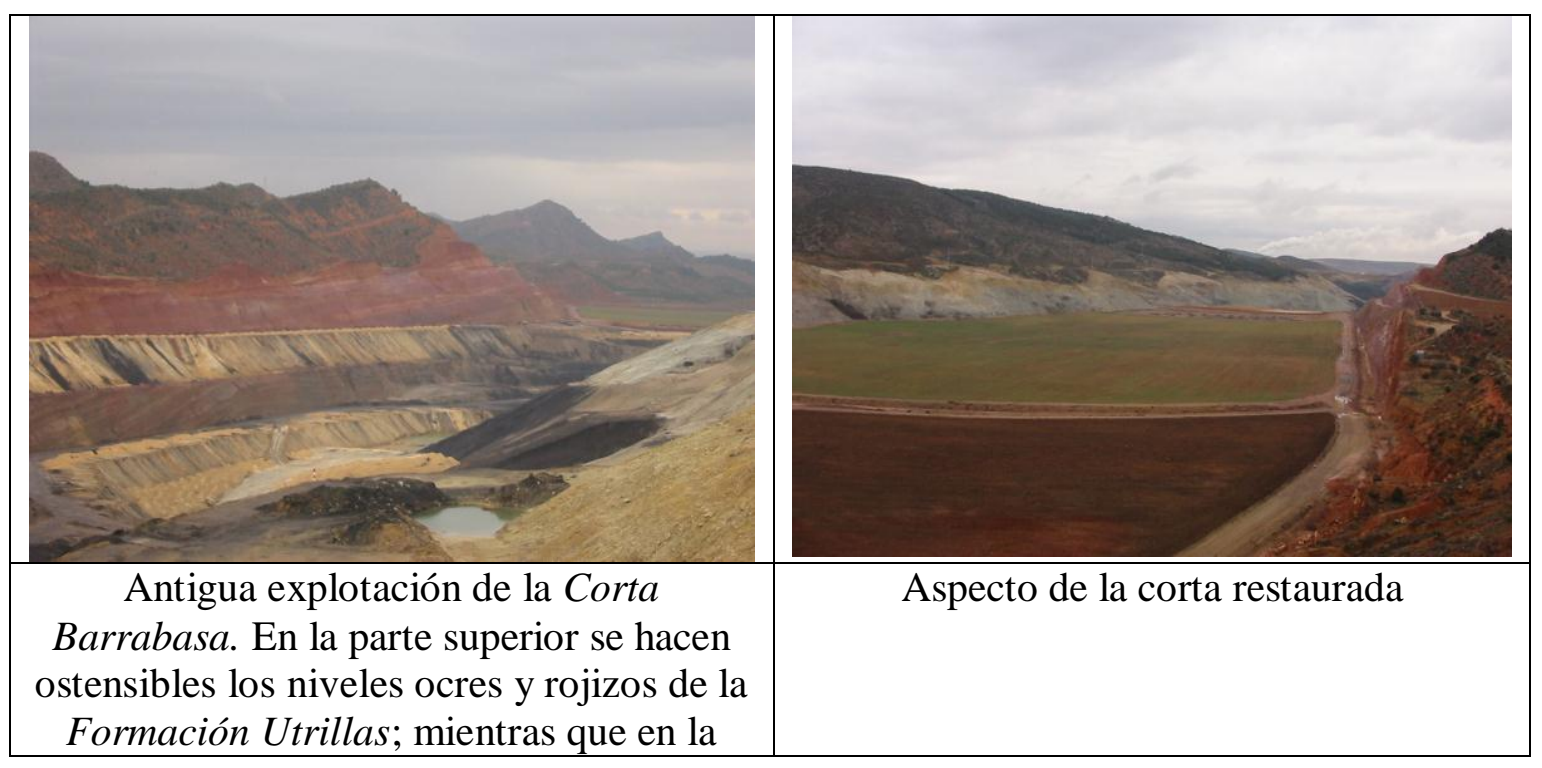


parte inferior se ven los niveles negruzcos de la Formación Escucha. Por debajo de estos, a la derecha de la fotografía aparecen los materiales carbonatados del Cretácico Inferior

PARADA 3 - CONDICIONAL. EXPLOTACIONES DE ARIÑO, (término municipal de Ariño, comarca de la Sierra de Arcos - Andora). (Hoja 494).

Después de realizar la parada anterior, es necesario continuar por la carretera que conduce a Ariño, por el denominado Valdeariño. En este sector se van encontrando diversas explotaciones mineras (algunas de ellas subterráneas). Al llegar a las inmediaciones de Ariño, es posible ver una gran explotación, la cual se realiza a cielo Abierto, por parte de la Empresa SAMCA. Naturalmente, para visitarla es necesario tener la autorización de la empresa.

En este recorrido desde la parada anterior, habremos ido encontrando los materiales que ya hemos mencionado anteriormente. Estos materiales pertenecen al Albiense, distribuyéndose entre la Formación Utrillas y la Formación Escucha. Precisamente, en la corta afloran las dos. Ello da lugar a que se trate de una doble explotación: de caolín y de lignito.

PARADA 4 - CONDICIONAL. CENTRO DE INTERPRETACIÓN DEL PARQUE CULTURAL DEL RÍO MARTIN, (término municipal de Ariño, comarca de la Sierra de Arcos - Andora). (Hoja 494).

Después de realizar la parada anterior, es necesario continuar definitivamente hacía Ariño. Poco antes de llegar, se hace claramente ostensible el centro de interpretación del Parque Cultural del Río Martín. Ahí, a unos 2 Km de la anterior, efectuaremos una nueva parada.

En este recorrido, habremos ido encontrando los materiales mesozoicos del Cretácico que ya hemos mencionado anteriormente. Estos son también los materiales que afloran en el lugar de la parada.

En este lugar hay un interesante centro dedicado al conocimiento del Parque Cultural del Río Martín, y en especial de las numerosas pinturas rupestres que aparecen por los alrededores. 


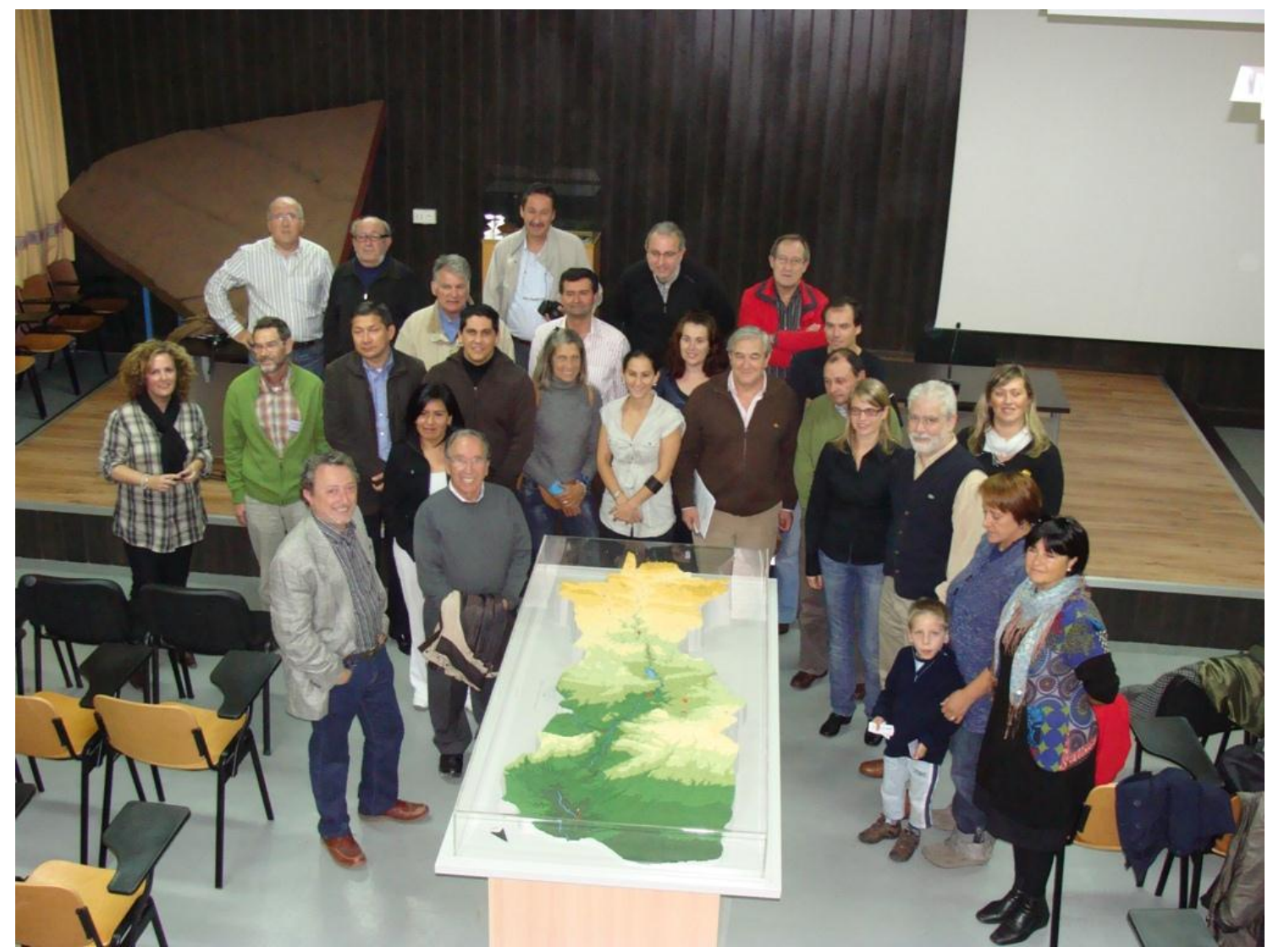

Un aspecto del interior del Centro, con parte de los asistentes al Congreso de Ariño (2010)

PARADA 5. LA SIMA DE SAN PEDRO, (término municipal de Oliete, comarca de la Sierra de Arcos - Andorra). (Hoja 494).

Después de realizar la parada anterior, será necesario llegar hasta las inmediaciones de Ariño. Luego. Convendrá iniciar una hijuela hacía el pueblo de Oliete. Sin embargo, al encontrar el camino que conduce a la Sima de San Pedro, convendrá tomarlo para llegar a este paraje. Así, en este lugar efectuaremos una nueva parada, a unos $7 \mathrm{Km}$ de la parada anteriormente efectuada.

En este recorrido, hemos ido encontrando afloramientos de los materiales mesozoicos carbonatados (que en su mayor parte pertenecen al Cretácico). Conviene decir que al pasar por las inmediaciones de Ariño; concretamente en el cruce de carreteras, hay un interesante yacimiento paleontológico.

Luego, al acercarnos al lugar de la parada, iremos encontrando afloramientos de los materiales carbonatados mesozoicos, que en su mayor parte pertenecen al Cretácico. Entre los materiales presentes cabe destacar los de características carbonatadas, fundamentalmente los calcáreos.

En estas circunstancias (y sobre estos materiales) se han desarrollado unos interesantes procesos kársticas. Éstos han dado lugar a la formación de una de las simas más profunda de España; siendo al mismo tiempo una de las más profundad de Europa y del mundo. 


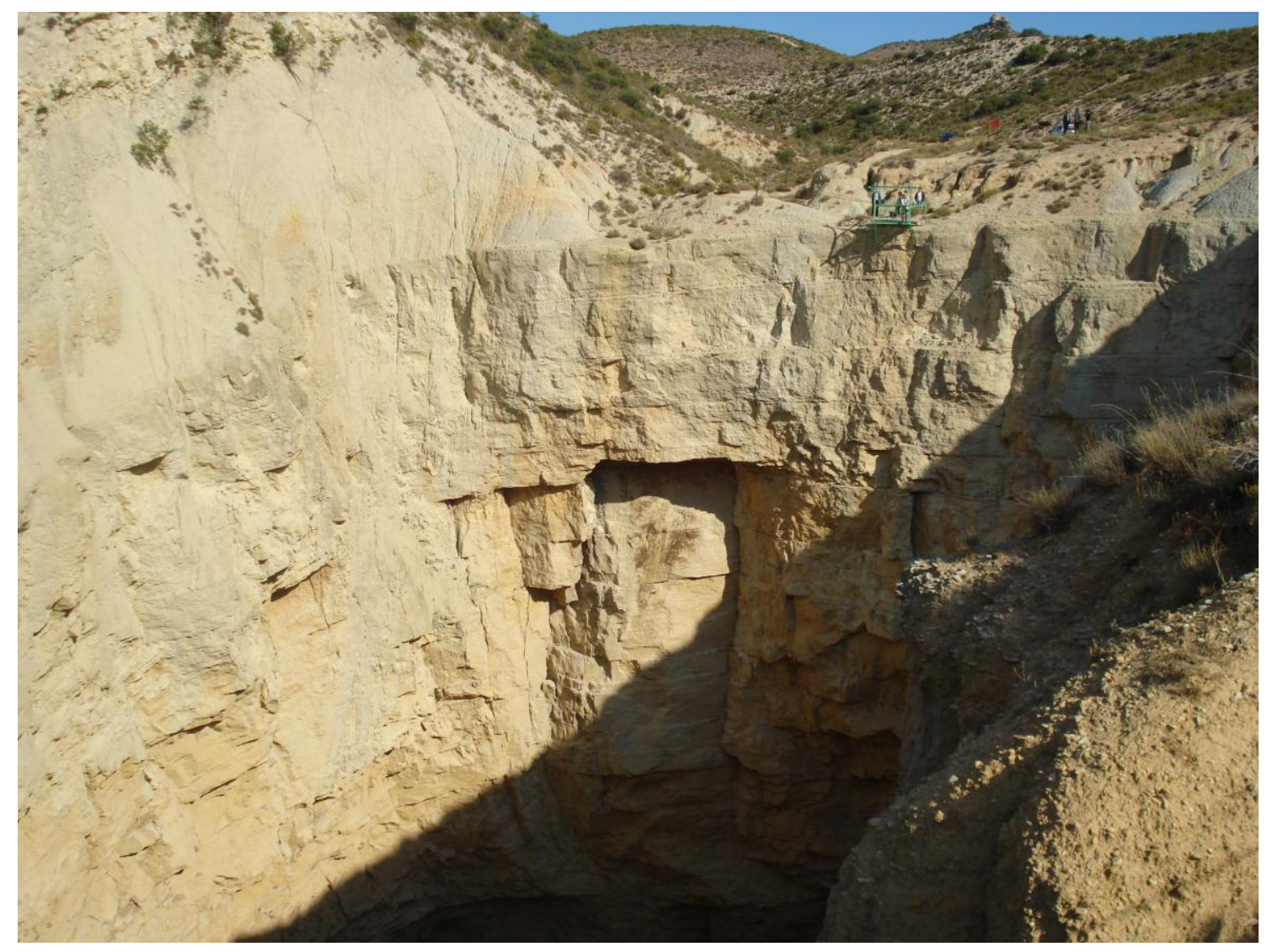

Sima de San Pedro

Este paraje es uno de los más importantes de Aragón y de la Península Ibérica, en relación al Patrimonio Geológico del mismo. 


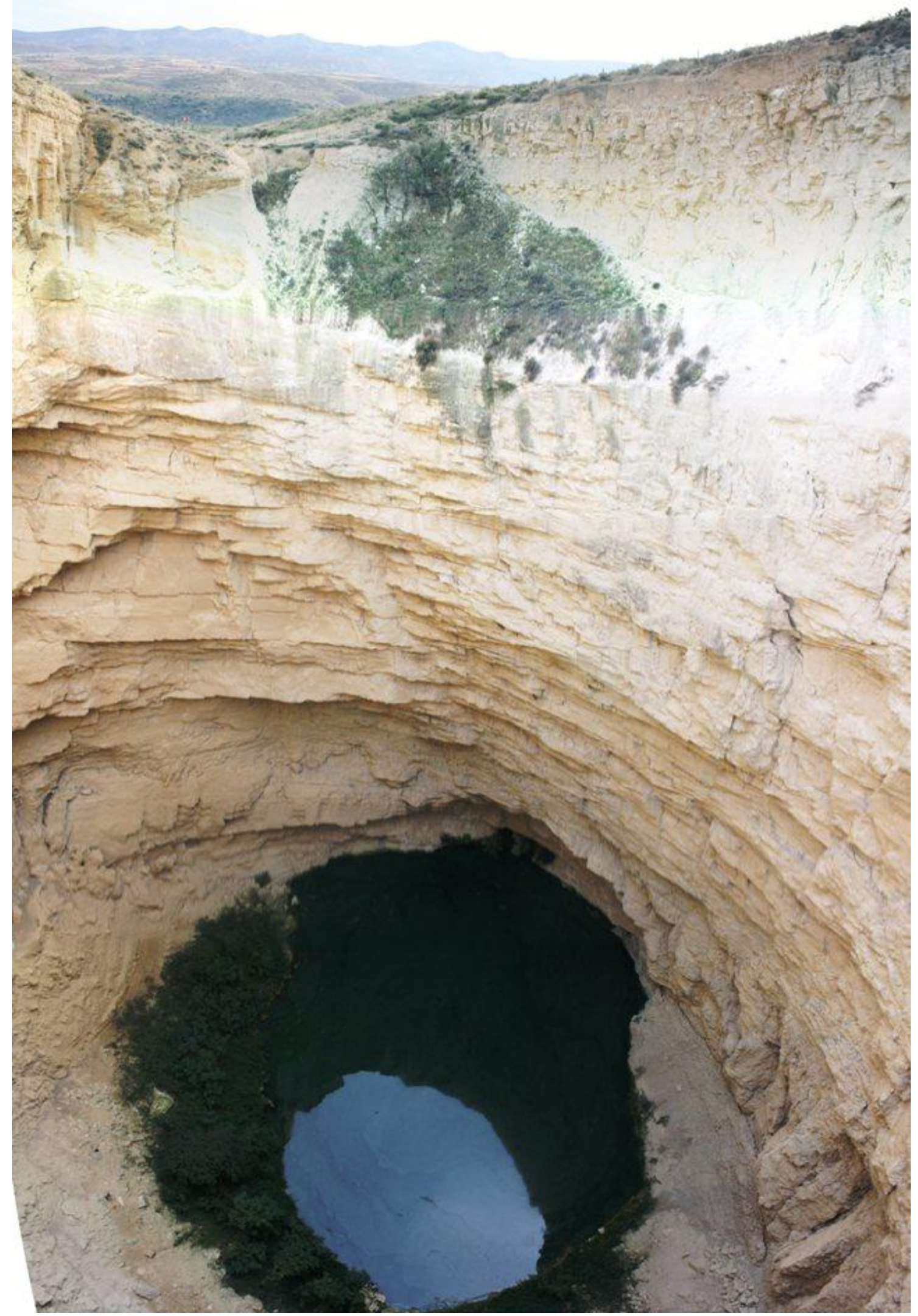

Un aspecto de la Sima de San Pedro

(Fotografía de Kamal Tarquisti, durante el Congreso de Ariño, 2010) 
PARADA 6. LOS BAÑOS DE ARIÑO, (término municipal de Ariño, comarca de la Sierra de Arcos - Andora). (Hoja 494).

Tras efectuar la parada anterior, es necesario retornar a la población de Ariño; luego nos convendrá seguir por la carretera que conduce hacía Albalate del Arzobispo. A poca distancia de Ariño, llegaremos al paraje de las Termas. Ahí efectuaremos una nueva parada, a unos $6 \mathrm{Km}$ de la anterior.

En este recorrido, como en los de los tramos anteriores, iremos encontrando afloramientos de los materiales mesozoicos que forman parte de la Rama Aragonesa del Sistema Ibérico, en donde ahora estamos situados.

A menudo, estos terrenos se hallan recubiertos por terrenos detríticos cuaternarios, como ocurre con las terrazas fluviales del río Martín. Precisamente en las inmediaciones de Ariño, junto a la carretera hay una antigua explotación de áridos que aprovechaba estos materiales (PARADA 5 - BIS)

En este lugar hay unas antiguas termas. En ellas se aprovechaban las aguas termales procedentes de unas fuentes. Estas emanaciones se relacionan con una falla que costa a los materiales del Sistema Ibérico. Asimismo, al circular las aguas superficiales por esta falla, se ha provocado un aumento de la temperatura media.

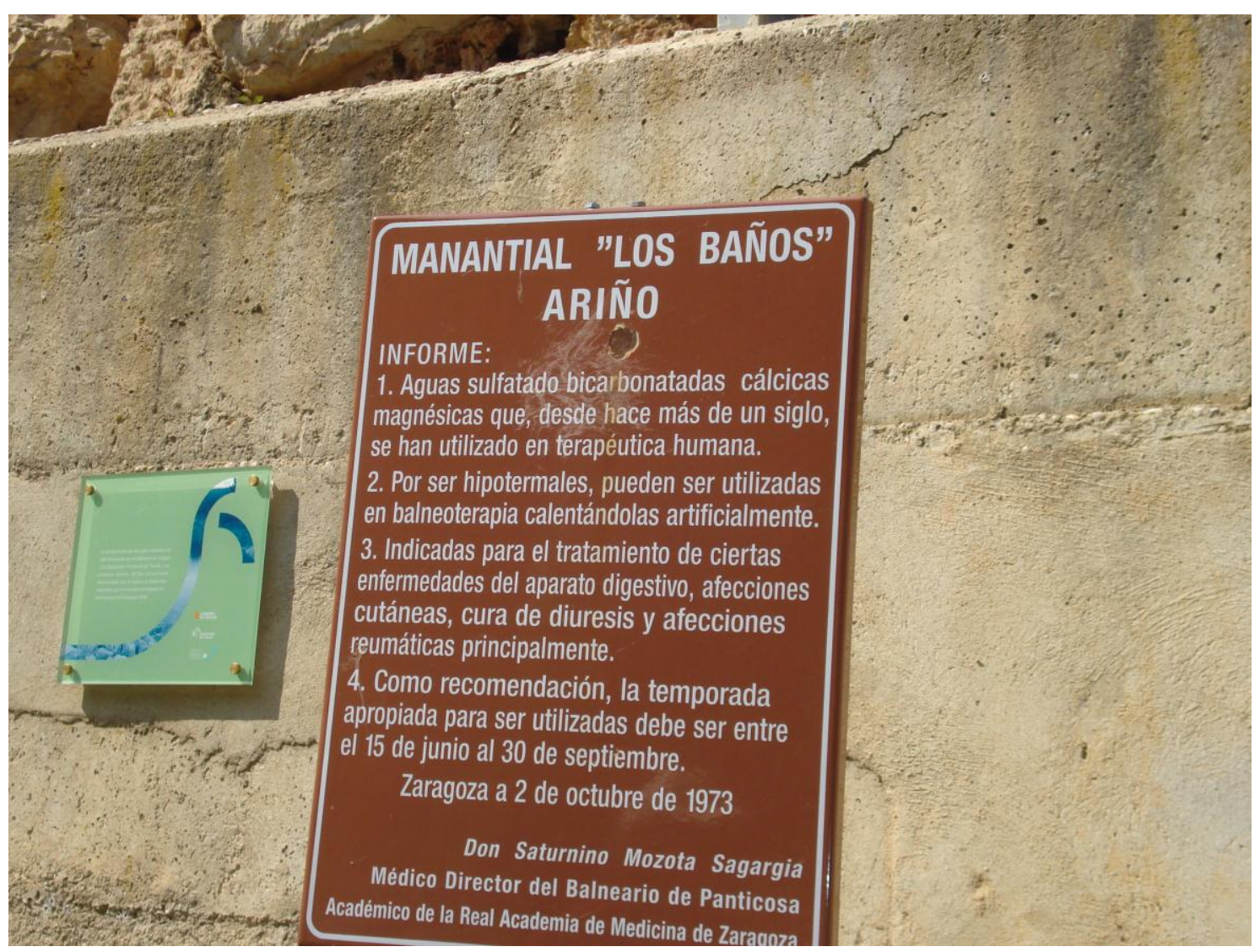

Cartel indicativo de los Baños de Ariño 


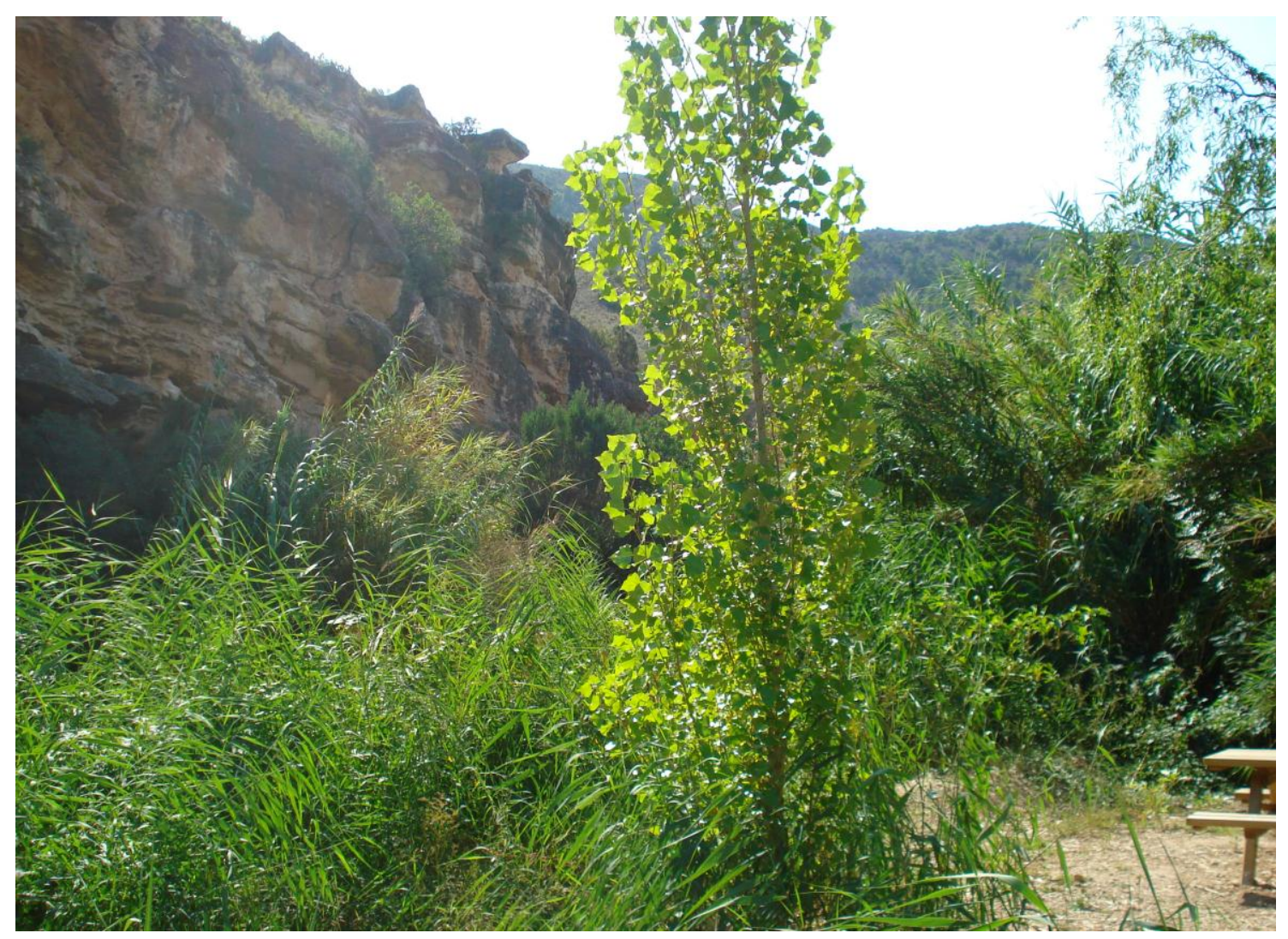

Paraje en donde brotan las aguas termales

En la actualidad, por parte del Ayuntamiento se está procediendo a la construcción de un Balneario más moderno, situado en las cercanías de la carretera (PARADA 6-BIS)

PARADA 7. LOS ESTRECHOS DEL RÍO MARTÍN, (término municipal de Albalate del Arzobispo, comarca del Bajo Martín). (Hoja 467).

Tras haber realizado la parada anterior, conviene continuar por la carretera que se dirige bacía la cercana población de Albalate del Arzobispo. Esta carretera va siguiendo el río Martín. Tras cruzar el río y pasar la carretera a su margen derecho, nos convendrá seguir hacía Albalate. A unos $3 \mathrm{Km}$ antes de llegar al pueblo, nos convendrá tomar un camino que sale por la izquierda de la carretera. Este camino se dirige a los estrechos del río Martín. Ahí efectuaremos una nueva parada, a unos $7 \mathrm{Km}$ de la anterior.

En este recorrido habremos ido cortando afloramientos de los materiales carbonatados mesozoicos. Estos son fundamentalmente del Cretácico. Sobre estos materiales, el río Martín ha escavado un interesante cañón. Al respecto del cañón, cabe indicar que en sus márgenes se han encontrado diversas pinturas rupestres.

Para visitar estas pinturas rupestres, es necesario seguir las indicaciones emanadas des del Centro de Interpretación del Parque Cultural del río Martín, situado en la localidad de Ariño (que hemos podido ver en la PARADA 4) 


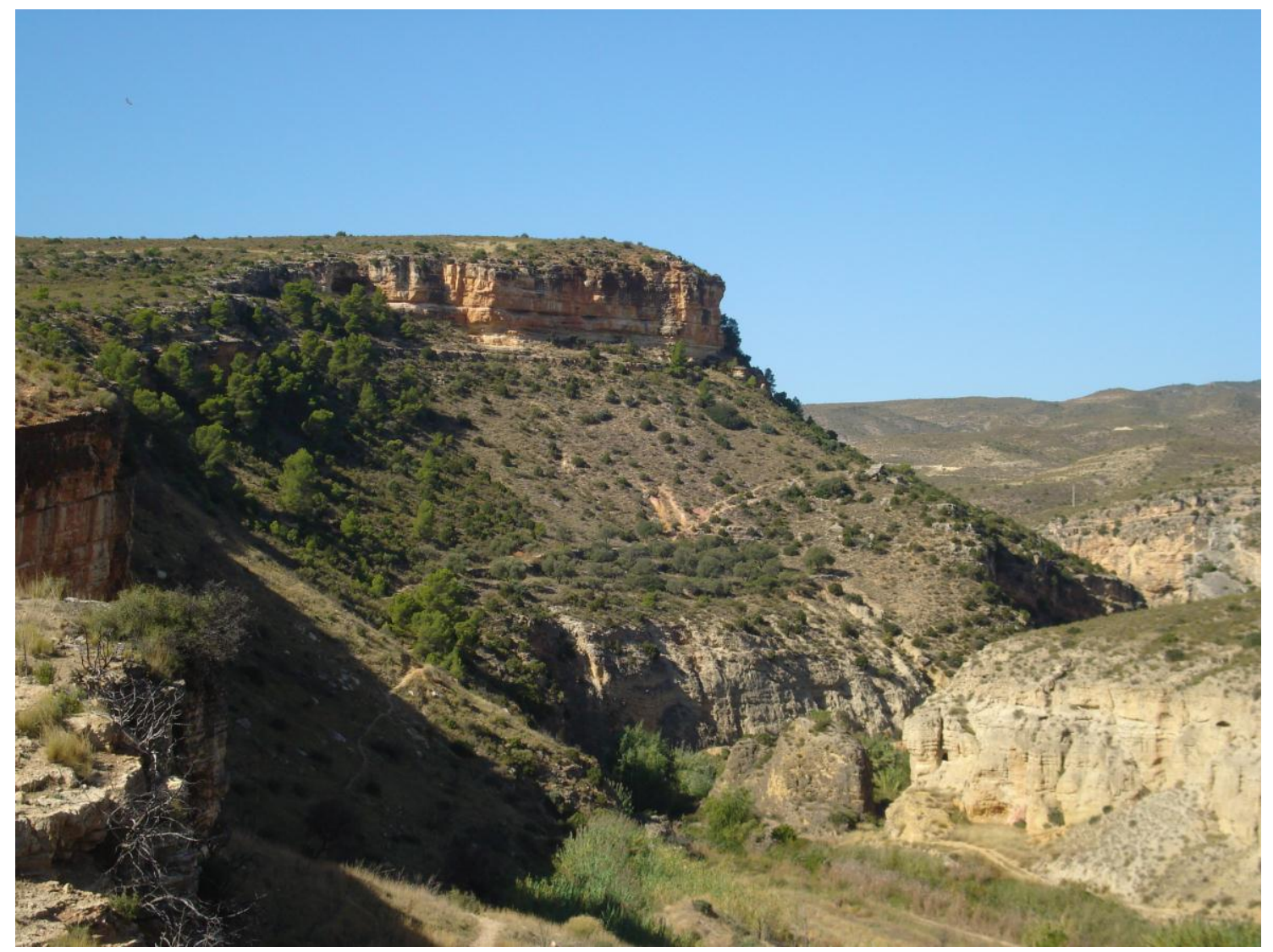

Un aspecto de los estrechos

PARADA 8. LOS TEJARES DE ALBALATE DEL ARZOBISPO, (término municipal de Albalate del Arzobispo, comarca del Bajo Martín). (Hoja 467).

Tras haber realizado la parada anterior, conviene continuar retornar a la carretera, con la finalidad de llegar a Albalate del Arzobispo. Al llegar a la población, conviene seguir por la que se dirige a Lecera. Casi en la misma salida, efectuaremos una nueva parada a la derecha de las mismas. Esta parada la efectuaremos en uno de los antiguos tejares de la población.

En este recorrido, hemos dejado atrás los afloramientos de los materiales mesozoicos de la Rama Aragonesa del Sistema Ibérico, entrando ahora en la Depresión Geológica del Ebro. Así, ahora habremos empezado encontrar afloramientos de los niveles cenozoicos que rellenan la mencionada depresión. Por otra parte, hemos visto diversas explotaciones (antiguas) de los materiales terciarios.

En este lugar había explotaciones de los materiales arcillosos terciarios (a la izquierda de la carretera). Estos materiales eran utilizados por unos antiguos tejares situados a la derecha de la carretera. 


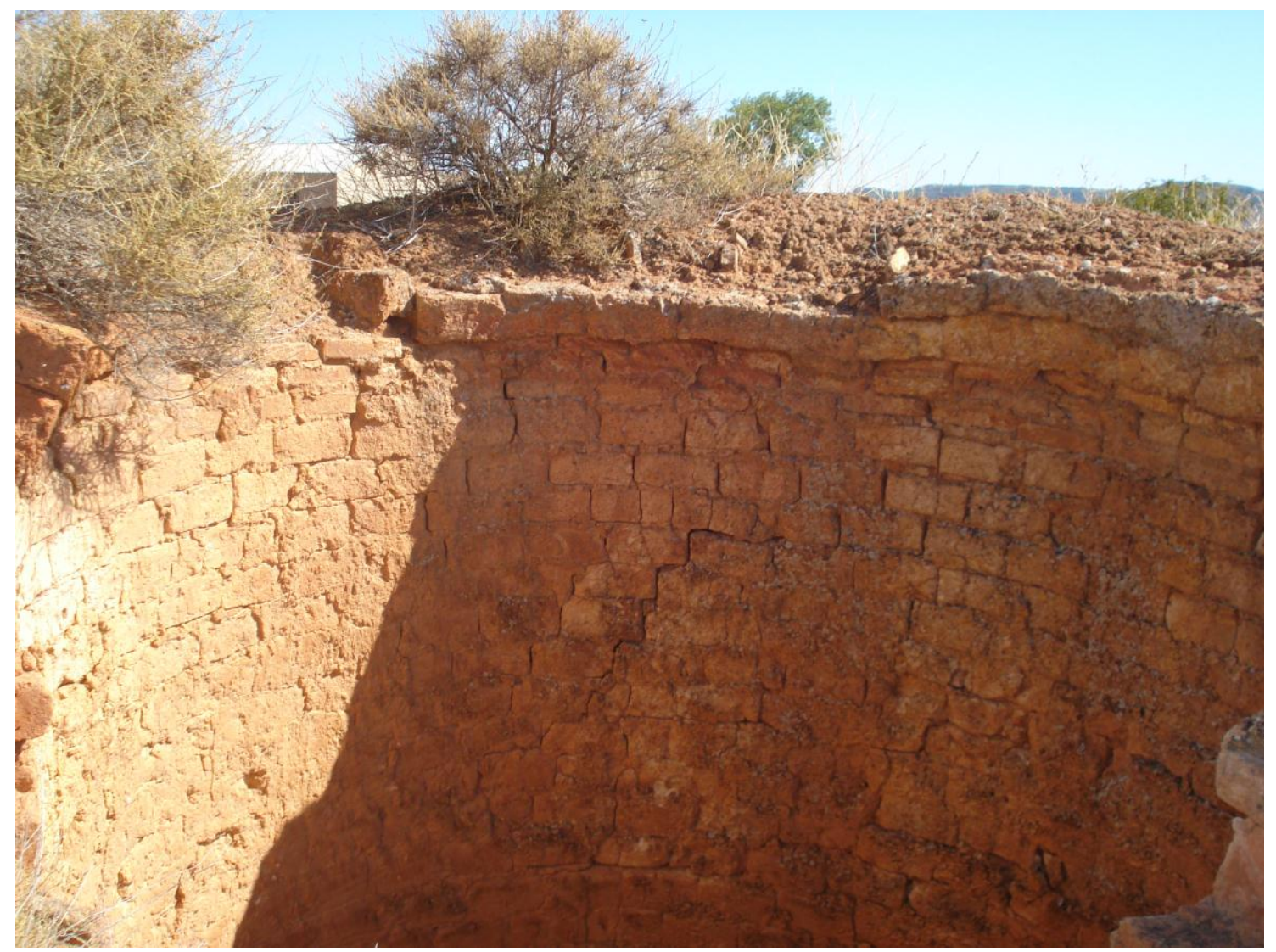

Restos de uno de los tejares

\section{EN ESTE LUGAR FINALIZA EL RECORRIDO DEL PRESENTE ITINERARIO}

\section{BIBLIOGRAFIA}

CALVO, M. Et altri (1988).- Minerales de Aragón. Colección: temas geológicos, Edit. Mira, 210 pag. Zaragoza

GADMA. (2001).- Puntos de Interés Geológico de Aragón, Edit. Gobierno de Aragón, Departamento de Medio Ambiente (GADMA). 243 pag. Zaragoza

MAESTRE, A. (1845).- Descripción geognóstica del Distrito Minero de Aragón y Cataluña. Anales de Minas, t. III, Madrid

MATA-PERELLÓ, J.M. (1987).- Introducción al conocimiento de las mineralizaciones aragonesas. Mineralogistes de Catalunya, t.III, pp. 258-265. Barcelona

MATA-PERELLÓ, J.M. (1991).- Inventario Mineralógico de la comarca del Maestrazgo. Rodeno, no 33. 15 pag. Manresa 
MATA-PERELLÓ, J.M. (1991).- Inventario Mineralógico de la comarca de la Tierra de Montalbán. Rodeno, no 35.34 pag. Manresa

MATA-PERELLÓ, J.M. (1996).- Recerca geológica i mineralògica per les comarques de la Tierra de Montalbán, de la Tierra Baja-Martín i de la Tierra Baja-Guadalope: des d'Alcañís a Andorra, Aliaga i a la Zoma. Algeps, sèrie B. 15-extra. 21 pag. Manresa

MATA-PERELLÓ, J.M. (1997).- Recerca geológica i mineralògica per les terres aragoneses dels Monegros, de la Tierra de Montalbán, de la Tierra Baja-Martín i de la Tierra Baja-Guadalope: des de Bujaraloz a Puig Moreno i a Aliaga.. Xaragall, sèrie B. 61, 10 pag. Manresa

MATA-PERELLÓ, J.M. (2002).- Recorrido geológico y mineralógico por la Tierra de Montalbán: desde Utrillas a la Zoma y al Parque Geológico de Aliaga. Inèdito.7 páginas. Manresa.

MATA-PERELLÓ, J.M. (2003).- Recorrido geológico y mineralógico por la Tierra de Montalbán y por el Maestrazgo: desde Utrillas y Escucha al Parque Geológico de Aliaga y a Cantavieja. Inèdito.7 páginas. Manresa.

MATA-PERELLÓ, J.M. (2009).- Recorrido geológico y mineralógico por las comarcas de la Sierra de Arcos - Andorra y del Bajo Martín: desde Andorra a Ariño y Albalate del Arzobispo. Inèdito. 12 páginas. Manresa

PEÑA MONGE, J.L. et altri (1984).- Geomorfología de la provincia de Teruel. Pub. Inst. Estudios Turolenses, 149 pag

PRAMES (2005).- Andorra - Siera de Arcos. Colección RUTASCAL por Aragón. Prames, Gobierno de Aragón. 119 pag. Zaragoza. 